\title{
Moral Values and Attitudes Toward Dutch Sow Husbandry
}

\author{
Tamara J. Bergstra • Bart Gremmen • \\ Elsbeth N. Stassen
}

Accepted: 22 February 2015/Published online: 15 March 2015

(C) The Author(s) 2015. This article is published with open access at Springerlink.com

\begin{abstract}
Attitudes toward sow husbandry differ between citizens and conventional pig farmers. Research showed that moral values could only predict the judgment of people in case of culling healthy animals in the course of a disease epidemic to a certain extent. Therefore, we hypothesized that attitudes of citizens and pig farmers cannot be predicted one-on-one by moral values. Furthermore, we were interested in getting insight in whether moral values can be useful in bridging the gap between attitudes toward sow husbandry of citizens and pig farmers. Based on a questionnaire, it was found that pig farmers and citizens, when considered as one group, shared the valuation of most moral values. However, when studying the four clusters of citizens with different attitudes toward sow husbandry, determined in a previous study, a variation in valuation of the moral values between the clusters of citizens and farmers came to the fore. This means that moral values are interpreted differently by groups of people when forming attitudes toward sow husbandry. The results of our study give an indication of which moral values are weighed differently between clusters of citizens and pig farmers. This information can be useful in future research on attitudes toward animal husbandry in order to understand why attitudes differ between groups of people. Besides, our results can
\end{abstract}

\footnotetext{
T. J. Bergstra $(\bowtie)$

Department of Social Sciences, Chair Group Business Economics, Wageningen University, Hollandseweg 1, $6706 \mathrm{KN}$ Wageningen, The Netherlands

e-mail: tamarabergstra@hotmail.com

B. Gremmen

Department of Social Sciences, Chair Group Philosophy, Wageningen University, Wageningen, The Netherlands

e-mail: gremmen@wur.nl

E. N. Stassen

Department of Animal Sciences, Chair Group Animals in Society, Wageningen University, Wageningen, The Netherlands

e-mail: elsbeth.stassen@wur.nl
} 
be useful for the pig sector and citizens to learn to understand each other's attitudes. With this understanding it is possible to invest in a husbandry system that can build on societal support.

Keywords Attitudes · Moral values · Naturalness · Sow husbandry

\section{Introduction}

In the last decades, societal concerns about animal husbandry systems have increased and became more prominent (Barnett et al. 2001; Bergstra et al. 2013; De Barcellos et al. 2012; Krystallis et al. 2009; María 2006; Mench 2008; Meuwissen and van der Lans 2005; Ngapo et al. 2003; Schröder and McEachern 2004). One of the husbandry systems that has been confronted with societal concerns is sow husbandry. With regard to sow husbandry there are, for example, concerns about castration and tail docking without anesthesia, pig housing (e.g., surface, social contact and environmental enrichment) and the use of antibiotics (Barnett et al. 2001; Bergstra et al. 2013; Boogaard et al. 2011b; Frederiksen et al. 2010; Marchant-Forde 2009; Millman 2011). There are also concerns about human health and the environmental consequences with regard to animal husbandry (Bergstra et al. 2013; Brom 2000; Harper and Henson 2001; Harper and Makatouni 2002; McGlone 2001; Verbeke and Viaene 2000; Webster 2001). Most of these societal concerns arise from negative attitudes of citizens toward sow husbandry. Between citizens and other stakeholders, major differences in these attitudes and attitudes toward sow husbandry in general have been reported (Bergstra et al. 2013; Bock and van Huik 2007; Lassen et al. 2006; Te Velde et al. 2002; Tuyttens et al. 2010; Van Huik and Bock 2007; Vanhonacker et al. 2008). The focus of this paper will be on two Dutch stakeholder groups, i.e., citizens and conventional pig farmers, because these groups play a crucial role in societal concerns about sow husbandry. In the remainder of this paper, pig farmer stands for conventional pig farmer.

Attitudes expressed in public debates originate in moral values (Rokeach 1968). Moral values can be defined as normative values that have evolved in such a way that people can interact with one another (Krebs and Denton 2005). Being able to interact with one another means that people have to share morality (Krebs and Denton 2005). However, the underlying reasoning of morality may differ between individuals (Krebs and Denton 2005), depending on culture, science, education, social background and legislation (Fraser 1999). The moral reasoning and how moral values are being weighed depends on the context (Cohen et al. 2010). In the context of a specific animal husbandry, moral values have an influence on the general acceptance of this animal practice (Fraser 2008). For example, modern dairy farm practices are more accepted by people who opt for the moral value that humans are superior to animals than by people who opt for the moral value that humans and animals are equivalent (Boogaard et al. 2011a). Also the moral value that farm animals are being sentient has an influence on the acceptance of animal husbandry practices (Duncan 2006; Knight et al. 2004). When a farm animal is considered to 
be sentient, the effect of animal husbandry practices on pain and/ or distress of the animal has to be justified before the animal husbandry practice can be accepted (Knight et al. 2004).

Although several studies have included moral values of farmers and citizens (Te Velde et al. 2002; Tuyttens et al. 2010; Vanhonacker et al. 2008) they did not focus on a specific context. With regard to a certain context all individual moral values will be weighed relative to each other in order to form attitudes (Cohen 2010a, b). This could lead to a situation in which people with the same set of moral values could develop different attitudes. In such a situation it becomes difficult to predict attitudes based on information about moral values. Cohen et al. (2010, 2012) concluded that moral values could only predict the judgment of culling healthy animals in the course of a disease epidemic to a certain extent, e.g. when the moral value 'respect for animal life' was considered important this person was most likely against the culling of healthy animals. In this paper we will try to generalize the findings of Cohen et al. (2010, 2012) to Dutch sow husbandry as a whole by testing the hypothesis that moral values of citizens and pig farmers cannot predict one-toone the attitudes toward sow husbandry of these groups. Nevertheless, it is of importance to know if citizens share the same set of moral values with pig farmers in order to understand how these moral values are being weighed and which moral values are considered most important. Knowledge about how these moral values are being weighed may enable the possibility to predict the attitudes of citizens and pig farmers toward sow husbandry. Knowing which moral values are weighed similar and which ones are weighed differently between citizens and pig farmers might make it possible to understand the difference in attitudes toward sow husbandry between these two groups. This understanding is useful for farmers and policy makers in the choices they make and in their communication toward citizens. When they know how citizens weigh their moral values and how this weighing differs from their own weighing, they might be able to predict how citizens respond to certain made choices and provided information. Knowing how different groups of people weigh their moral values is also useful for future research in order to understand where attitudes are based on. Understanding the weighing of the underlying moral values gives possibilities to bridge the gap between the different attitudes toward sow husbandry of citizens and pig farmers. This means that it might be possible to reduce the distance in these attitudes between citizens and pig farmers. This will make it possible for different groups of people to understand the attitudes toward sow husbandry of other groups. Different groups of citizens have different attitudes toward sow husbandry (Anonymous 2014). Therefore, it is of relevance to study these different groups. For groups of citizens we focus on the study of Anonymous (2014). In their study, Dutch citizens were asked to give a level of additional care (AC), i.e. the degree of extra attention compared to the current situation they found necessary, for different aspects of entities, i.e., animals, humans and the environment, related to sow husbandry. Based on these AC levels, citizens were divided into four clusters (Table 1). The two smallest clusters were the most extreme; the no-AC cluster (7\% of respondents) found no AC necessary for the aspects of sow husbandry and the max-AC cluster (14\% of respondents) found the most AC necessary compared to the other clusters. The high-AC cluster and the 
Table 1 The average additional care (AC) levels, i.e., the degree of extra attention that was found necessary compared to the current situation, on a five-point scale (1: no AC necessary, 5: maximal AC necessary) of clusters $(\mathrm{Cl})$ of citizens (based on AC levels) and pig farmers ( $\mathrm{Pf})$

\begin{tabular}{|c|c|c|c|c|c|c|}
\hline Entity & Aspect & $\mathrm{C} 11^{*}$ & $\mathrm{Cl} 2$ & $\mathrm{Cl} 3$ & $\mathrm{Cl} 4$ & Pf \\
\hline \multirow[t]{20}{*}{ Animals } & Metabolic/physical exhaustion & 3.7 & 3.0 & 4.5 & 1.7 & 2.7 \\
\hline & Rate sickness/infection/injury & 4.2 & 3.3 & 4.8 & 2.1 & 3.0 \\
\hline & Mortality & 4.1 & 3.1 & 4.6 & 1.9 & 2.9 \\
\hline & Fear/anxiety & 4.3 & 3.3 & 4.8 & 2.1 & 2.6 \\
\hline & Pain & 4.4 & 3.3 & 4.8 & 2.0 & 2.6 \\
\hline & Number of kept animals & 4.4 & 3.4 & 4.7 & 1.9 & 2.3 \\
\hline & Environmental enrichment & 4.0 & 3.1 & 4.5 & 1.8 & 2.5 \\
\hline & Number of animals per $\mathrm{m} 2$ & 4.4 & 3.4 & 4.8 & 2.0 & 2.3 \\
\hline & Floor cover & 4.3 & 3.3 & 4.8 & 2.0 & 2.3 \\
\hline & Possibility to go outside & 4.5 & 3.5 & 4.8 & 2.1 & 1.5 \\
\hline & Tail docking & 4.2 & 3.1 & 4.7 & 1.7 & 2.2 \\
\hline & Castration & 4.2 & 3.0 & 4.7 & 1.7 & 2.7 \\
\hline & Time euthanasia & 4.1 & 3.1 & 4.7 & 1.5 & 2.9 \\
\hline & Lifespan sow & 4.2 & 3.1 & 4.8 & 1.6 & 2.6 \\
\hline & Number of litters per sow & 4.1 & 3.1 & 4.8 & 1.7 & 2.3 \\
\hline & Litter size & 4.0 & 3.0 & 4.7 & 1.6 & 2.4 \\
\hline & Weaning age & 4.1 & 3.0 & 4.7 & 1.6 & 2.3 \\
\hline & Motherless care & 4.3 & 3.1 & 4.8 & 1.6 & 2.7 \\
\hline & Care for individual animal & 4.3 & 3.2 & 4.9 & 1.6 & 2.5 \\
\hline & Use of antibiotics (animal) & 4.5 & 3.7 & 4.9 & 3.0 & 3.2 \\
\hline \multirow[t]{6}{*}{ Animal keepers } & Enough income & 3.5 & 3.4 & 4.5 & 3.1 & 4.5 \\
\hline & Freedom to act & 3.2 & 3.2 & 4.1 & 2.7 & 3.7 \\
\hline & Working conditions & 3.5 & 3.3 & 4.6 & 2.5 & 3.4 \\
\hline & Health risks & 3.9 & 3.5 & 4.9 & 2.6 & 3.3 \\
\hline & Physical burden & 3.6 & 3.3 & 4.7 & 2.4 & 3.4 \\
\hline & Mental burden & 3.5 & 3.3 & 4.7 & 2.5 & 3.8 \\
\hline \multirow[t]{6}{*}{ Consumers } & Price product & 3.3 & 3.2 & 4.4 & 2.3 & 4.1 \\
\hline & Freedom of choice & 3.4 & 3.1 & 4.4 & 2.5 & 3.2 \\
\hline & Food safety risks & 4.2 & 3.6 & 4.9 & 2.7 & 2.8 \\
\hline & Public health risks & 4.3 & 3.7 & 5.0 & 2.8 & 2.8 \\
\hline & Use of antibiotics (human) & 4.4 & 3.8 & 5.0 & 3.2 & 3.2 \\
\hline & Experience meat products & 3.5 & 3.1 & 4.6 & 2.3 & 3.7 \\
\hline \multirow[t]{4}{*}{ Environment } & Environmental waste & 4.3 & 3.7 & 4.8 & 2.9 & 2.5 \\
\hline & Smell & 3.8 & 3.6 & 4.5 & 2.5 & 2.6 \\
\hline & Change in infrastructure & 4.0 & 3.3 & 4.6 & 2.5 & 2.5 \\
\hline & Image landscape & 3.8 & 3.2 & 4.5 & 2.6 & 2.7 \\
\hline
\end{tabular}

* Cl1 high-AC cluster $(\mathrm{n}=645), C l 2$ moderate-AC cluster $(\mathrm{n}=623), C l 3$ Max-AC cluster $(\mathrm{n}=225)$, Cl4 no-AC cluster $(\mathrm{n}=114)$, Pf pig farmer $(\mathrm{n}=181)$ 
moderate-AC cluster were in between the former two cluster in terms of AC levels, with the high-AC cluster having higher AC levels than the moderate-AC cluster (Table 1). The AC levels of pig farmers were determined by Anonymous (2015; Table 1). Their results clearly show the differences in attitudes toward sow husbandry of the different clusters of citizens and pig farmers.

Given the differences between citizens and pig farmers in attitudes toward sow husbandry, the main question of this paper is whether these groups also valuate moral values in relation to sow husbandry differently. The objectives of this study were: (1) to describe a theoretical framework of moral values and attitudes related to sow husbandry, (2) to determine and compare moral values related to sow husbandry of (clusters of) citizens and pig farmers, (3) to test the hypothesis that moral values of citizens and pig farmers cannot predict one-on-one the attitudes toward sow husbandry of these groups, and (4) to find out how moral values can be useful in bridging the gap between attitudes toward sow husbandry of (clusters of) citizens and pig farmers.

\section{Theoretical Framework}

As a first step in this study, a theoretical framework was described (Fig. 1). Related to this framework, different definitions will be used in the remainder of this article. These definitions are explained in Fig. 2.

\section{Attitudes}

The lower part of the theoretical framework is related to attitudes toward sow husbandry.

Eagly and Chaiken (1993) define attitude as 'a psychological tendency that is expressed by evaluating a particular entity with some degree of favor or disfavor'. This means that people's attitudes are evaluations of an object, in this case sow husbandry. A person has to encounter the object and evaluate it on an affective, cognitive or behavioral basis to form an attitude (Eagly and Chaiken 1995). The theoretical framework has been developed in earlier work (Anonymous 2014). This is also the work in which the four clusters of citizens described in the introduction were determined, meaning that the aspects presented in Table 1 are based on this part of the framework. With regard to sow husbandry, attitudes are directed toward three entities, i.e. animals, humans and the environment. In relation to each entity, various aspects might be of influence on the attitudes people hold toward sow husbandry. Aspects of relevance for sow husbandry were selected based on literature (Anonymous 2014) and were related to issues of sow husbandry that have arisen in the Dutch media, from the year 2009 till 2011: piglet mortality, housing of pigs, scale increase of sow husbandry, interventions (castration, tail docking) in piglets, euthanasia of pigs, lifespan sow, piglet litter size, weaning age of piglets, motherless care of piglets, use of antibiotics in pigs and anesthetics used to sedate pigs. All issues and the related relevant aspects are included in the framework. The use of anesthetics was covered by the issue 'castration' because the discussions 


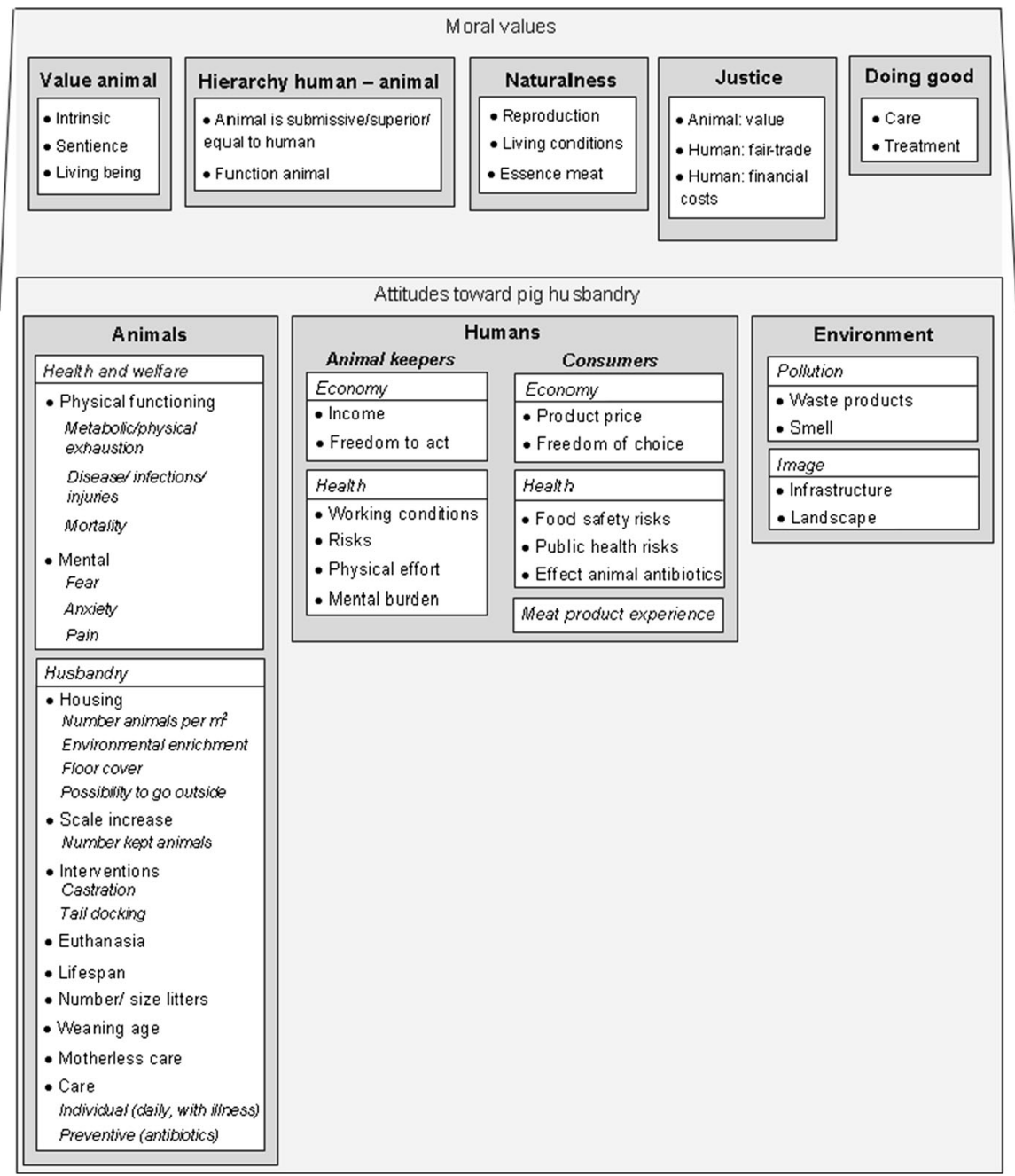

Fig. 1 Framework for the assessment of moral values and attitudes toward pig husbandry. For moral values, factors are shown toward which moral values are directed with regard to pig husbandry. For attitudes, aspects per entity, i.e., animals, humans and the environment, are shown toward which attitudes are directed with regard to pig husbandry

about castration predominantly focused on whether or not to use anesthetics during the castration process.

\section{Moral Values}

The upper part of the theoretical framework is related to moral values with regard to sow husbandry. For the moral values the following elements were distinguished: value animal, hierarchy human-animal, naturalness, justice and doing good. These 


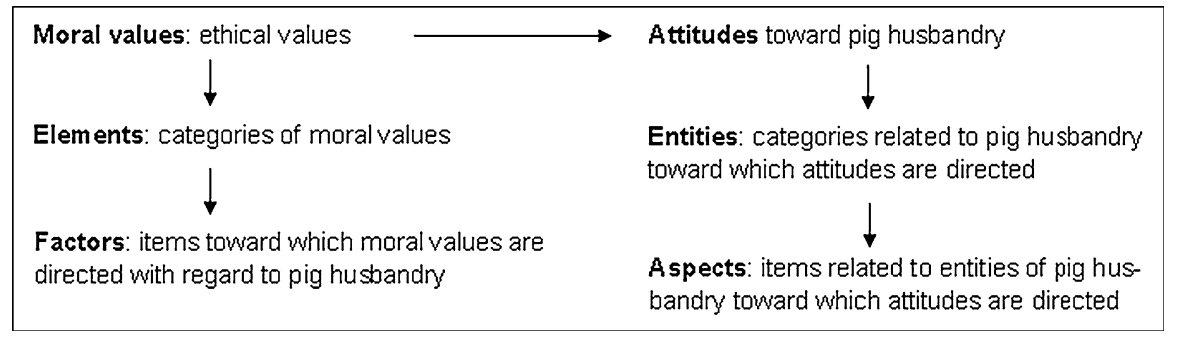

Fig. 2 Definitions used related to the framework (Fig. 1)

elements were considered relevant for sow husbandry based on literature (Mepham 2000; Michalopoulos et al. 2008; Cohen et al. 2009). Both Mepham (2000) and Cohen et al. (2009) included the value of animals in their ethical model for animal production. Cohen et al. (2009) also included human-animal hierarchy, doing good to animals and the rights of animals. The rights of animals indicated the right to life of animals when it concerned the killing of healthy animals in an epidemic outbreak. As the focus of our framework was not on the killing of healthy animals, the right of animals was not included separately but was grouped under 'value animal'. Mepham (2000) included factors of the elements 'naturalness', i.e., behavioral freedom, and 'justice', and 'justice', i.e., fair-trade. Naturalness and economic fairness were included in the model of Michalopoulos et al. (2008), for analyses on public acceptability of production systems. It was stated that the same model, with some additions, could be used for animal production systems (Michalopoulos et al. 2008). In our framework, all elements of the moral values were divided into factors. The factors were mostly related to two kinds of moral values in public debates about sow husbandry: moral values related to animals, which are used to develop attitudes toward sow husbandry with respect to animal welfare, health and housing (see lower part of framework; Fig. 1), and moral values related to humans which are used to develop attitudes toward sow husbandry with respect to animal keepers and consumers (see lower part of framework; Fig. 1). Explanations of the factors are given in Table 2. The elements and factors of the moral values in the theoretical framework were validated by experts in the field of sow husbandry and animal welfare.

\section{Materials and Methods}

\section{Data Collection}

Based on the aforementioned theoretical framework a questionnaire was developed. The first part of the questionnaire included questions related to moral values. For all factors, except the factor 'animal (pig) is superior/equivalent/submissive to human', a theorem was given, such as 'pigs are sentient'. Per theorem respondents could indicate whether they strongly disagreed, disagreed, were neutral, agreed or strongly 
Table 2 Description of elements and factors of moral values that play a role in pig husbandry

\begin{tabular}{lll}
\hline Element & Factor & Description \\
\hline
\end{tabular}

\section{Value animal Intrinsic}

Sentience

Living being

\section{Hierarchy \\ human- \\ animal}

Naturalness

Reproduction

Living conditions

Essence meat

Justice

Animal: value

Human: fair-trade

Human: financial costs

Doing good Care

Treatment
The intrinsic value is an animal's own value, independent of the value it has for humans, and is proven to be important in the evaluation of animals (Cohen 2010a, 2010b) and animal production systems (Mepham 2000)

Sentience is the animal's ability to feel pain and joy. Sentience is important in animal evaluation as animal welfare is mainly about feelings and animal experiences (Cohen 2010a, b, Duncan 2006)

When an animal is seen as a living being it has value. Animal value is proven to be important in animal evaluation (Cohen et al. 2009)

The position someone has with respect to animals plays a role in animal evaluation (Cohen 2010a, b)

What one finds to be the function of an animal, e.g. animals have to serve humans, plays a role in animal evaluation

In an ethical debate about killing animals it was argumented that animals have the right to have a natural lifecycle, i.e. lifespan, reproduction, age of giving first birth, longevity (Asseldonk et al. 2005). Reproduction is maximized in pig production so the level of natural reproduction plays an important role in pig husbandry evaluation

People want animals to have natural living conditions in which they can perform natural behaviour (Boogaard 2011a, b). This naturalness plays a role in the assessment of animal welfare (Mepham 2000, Tuyttens 2010, Vanhonacker et al. 2008, 2012)

Meat is seen as a part of humans' diet (Aarts 2001). The importance of pig meat plays a role in the evaluation of pig husbandry

The value of an animal will have an influence on how much justification an animal needs (Asseldonk et al. 2005). In the evaluation of animal production systems, justice in relation to animal value is of importance (Mepham 2000)

Justice on fair-trade is important in the ethical debate about animal production systems (Driessen 2012, Mepham 2000) and food concerns (Michalopoulos et al. 2008). In earlier research it is found that concerns exist about fair-trade (Driessen 2012)

Justice on financial costs (affordable food) is important in the ethical debate (Mepham 2000). In earlier research it is found that concerns exist about human wealth, i.e. farmer income and regional economy (Driessen 2012)

People believe that humans have to care for all animals (Cohen 2010a, b). The level of care that should be given is taken into consideration in the evaluation of pig husbandry

People believe that humans have to protect all animals (Cohen $2010 \mathrm{a}, \mathrm{b})$. A past of this protection is to treat animals when they are sick. How much treatment should be given is taken into consideration in the evaluation of pig husbandry

agreed. Besides including factors of the element 'naturalness' in this question, an extra question was added in which respondents could indicate what they found important with regard to naturalness. Respondents could indicate the level of 
importance (highly unimportant, unimportant, neutral, important, highly important) for different constituents of naturalness: possibility to go outside, social contact, freedom of movement, possibility to grub and mud bathe, good floor cover and ad libitum food and water. These levels of importance could indicate whether respondents interpret naturalness differently. In a separate question respondents could indicate whether they found animals superior, equivalent or submissive to humans.

The questionnaire also included questions about socio-demographic features, i.e., gender, age, level of education, religious (yes, no or a little), pets (yes or no) type of meat eaten, urban character of residence, region of residency in the Netherlands (north, middle or south) and size of childhood residence. The full questionnaire is available by contacting the first author of this paper.

The questionnaire was distributed via internet to citizens and pig farmers. A panel of 2572 randomly selected citizens were invited, by a research institute with a directory of Dutch citizens representative for the Netherlands, to participate and could fill in the questionnaire 2 weeks of October 2011 (CentERdata, Tilburg, the Netherlands). One week after the invitation the panel received a reminder. Pig farmers were invited by an invitation letter. This letter was sent, after exclusion of pig farmers with $<50$ sows, to 1000 randomly selected addresses from 2399 pig farmers registered by TOPIGS (a global leader in pig breeding and artificial insemination, Helvoirt, the Netherlands). Two weeks after the first letter, the selected farmers received a reminder letter.

The response rates in the current study were as follows:

- Dutch Citizens: 1607 of $2572(62.5 \%)$ :

- High-AC cluster: 645 of 1607 (40.1\%)

- Moderate-AC cluster: 623 of 1607 (38.8\%)

- Max-AC cluster: 225 of $1607(14.0 \%)$

- No-Ac cluster: 114 of 1607 (7.1\%)

- Dutch pig farmers: 181 of 1000 (18.1\%).

The socio-demographic features of these groups are presented in Table 3. In general, respondents of citizens were representative for the Netherlands, except for age. Citizens respondents were on average older $(81 \%>40$ years $)$ than the Dutch population (59\% > 40 years) (Centraal Bureau voor de Statistiek 2011). Based on socio-demographic features (Table 3), the group of pig farmers was assumed to be representative for Dutch pig farmers because most pig farmers are male and lower educated.

\section{Data Analysis}

First, a descriptive statistical analysis was carried out to study the moral values of (clusters of) citizens and pig farmers. Scores per factor of the moral values were 
Table 3 Percentage respondents per category of the socio-demographic features of clusters of citizens $(\mathrm{Cl})$ and pig farmers $(\mathrm{Pf})$

\begin{tabular}{|c|c|c|c|c|c|c|}
\hline Socio-demographic feature & Category & $\mathrm{Cl1}^{\mathrm{a}}$ & $\mathrm{Cl} 2$ & $\mathrm{Cl3}$ & $\mathrm{Cl} 4$ & Pf \\
\hline \multirow[t]{2}{*}{ Gender } & Male & 51 & 60 & 48 & 64 & 95 \\
\hline & Female & 49 & 40 & 52 & 36 & 5 \\
\hline \multirow[t]{6}{*}{ Age } & $15-24$ & 2 & 5 & 3 & 4 & 1 \\
\hline & $25-34$ & 5 & 5 & 2 & 7 & 15 \\
\hline & $35-44$ & 13 & 17 & 9 & 15 & 32 \\
\hline & $45-54$ & 21 & 20 & 12 & 25 & 39 \\
\hline & $55-64$ & 27 & 23 & 36 & 25 & 13 \\
\hline & 65-older & 33 & 29 & 38 & 23 & 0 \\
\hline \multirow[t]{6}{*}{ Education } & Primary school & 4 & 5 & 6 & 4 & 0 \\
\hline & Secondary school (low) & 26 & 25 & 40 & 22 & 4 \\
\hline & Secondary school (high) & 13 & 13 & 8 & 15 & 6 \\
\hline & Vocational & 16 & 16 & 16 & 15 & 59 \\
\hline & $\mathrm{BSc}$ & 28 & 27 & 23 & 28 & 28 \\
\hline & MSc & 13 & 15 & 6 & 15 & 2 \\
\hline \multirow[t]{3}{*}{ Religious } & Yes & 27 & 28 & 29 & 33 & 37 \\
\hline & No & 52 & 52 & 42 & 55 & 32 \\
\hline & A little & 22 & 20 & 28 & 12 & 31 \\
\hline \multirow[t]{2}{*}{ Pets } & Yes & 44 & 40 & 40 & 42 & 84 \\
\hline & No & 56 & 60 & 60 & 58 & 16 \\
\hline \multirow[t]{5}{*}{ Urbanity residence } & Extremely urban $\left(>2500^{\mathrm{b}}\right)$ & 16 & 12 & 16 & 10 & 4 \\
\hline & Highly urban (1500-2500) & 23 & 28 & 26 & 18 & 1 \\
\hline & Urban (1000-1500) & 23 & 18 & 27 & 22 & 2 \\
\hline & Moderate urban $(500-1000)$ & 20 & 25 & 17 & 31 & 18 \\
\hline & Not urban $(<500)$ & 18 & 18 & 15 & 19 & 74 \\
\hline \multirow[t]{5}{*}{ Childhood residence } & Randstad $^{\mathrm{c}}$ & 30 & 23 & 27 & 11 & 1 \\
\hline & Big city & 11 & 13 & 20 & 11 & 3 \\
\hline & Small city & 18 & 17 & 16 & 13 & 10 \\
\hline & Big town & 15 & 19 & 12 & 19 & 22 \\
\hline & Small town & 26 & 28 & 26 & 46 & 64 \\
\hline
\end{tabular}

${ }^{a} C l 1$ high-AC cluster $(\mathrm{n}=645), C l 2$ moderate-AC cluster $(\mathrm{n}=623), C l 3$ Max-AC cluster $(\mathrm{n}=225)$, Cl4 no-AC cluster $(\mathrm{n}=114)$, Pf pig farmer $(\mathrm{n}=181)$

b Number of inhabitants per square kilometer

c Randstad is the most urban area in the Netherlands

presented by the percentage of respondents per cluster of citizens and pig farmers that disagreed (including strongly disagreed), were neutral or agreed (including strongly agreed) with the theorem. For the human-animal position, percentages of respondents per cluster of citizens and pig farmers were calculated for each position (superior, equivalent and submissive). To indicate what was found important with regard to the factor 'naturalness' of the moral values, the percentages of respondents that found the constituents naturalness unimportant (including highly unimportant), 
were neutral or found the constituents important (including highly important) were presented.

Second, ordered multinomial logistic regression was performed for the valuation of factors, which were non-normal distributed and categorical, of the moral values, except for the human-animal position. The impact of group membership, i.e., either citizens or pig farmers, $\beta_{k}$ on levels of agreement for the factors of the moral values were estimated by maximizing the likelihood function $L\left(\boldsymbol{\beta}_{\boldsymbol{k}}\right)=$ $\prod_{i=1}^{N} \prod_{j=1}^{J}\left[\operatorname{Prob}\left(Y_{i}=j \mid \mathbf{x}_{i}\right)\right]^{I\left(y_{i}=j\right)}$, where Prob was the probability that respondent $i$ of the total numbers of respondents $N$ in group $k$ scored $j$ of the total number of choice options $j, I\left(y_{i}=j\right)=1$ if respondent $i$ choose score $j$ and 0 otherwise. In this analysis group membership and individual socio-demographic features were included as explanatory variables. Socio-demographic features were included because it is proven that these features have an effect on moral values (Fraser 1999). Of these variables, coefficient estimates and their significances were calculated. When there was a significant difference and the coefficient of $\beta_{k}$ was negative (or positive), the probability that respondent $i$ gave a lower (or higher) score than respondents in the other group became higher. More information about ordered multinomial logistic regression can be found in Greene and Hensher (2010).

Third, ordered multinomial logistic regression was performed for the valuation of all defined factors of the moral values and for levels of importance for constituents of naturalness, which were all non-normal and categorical. This time the clusters of citizens were included in group membership. The same equation as mentioned above was used with now $k$ being a cluster of citizens or the group of pig farmers. In this analysis only cluster membership was included as explanatory variable.

Fourth, a Kendall's Tau rank correlation analysis was carried out to study the correlation between the valuation of the moral values and AC levels assigned to aspects of sow husbandry (Table 1) and between the valuation of moral values and levels of importance for constituents of naturalness. Kendall's $\tau$ was defined by $\tau=(C-D) /\left(\frac{1}{2} n(n-1)\right)$, where $\mathrm{C}$ is the number of concordant pairs and $\mathrm{D}$ is the number of discordant pairs. To indicate the correlation, 0.6 was used as threshold because a correlation of $>0.6$ corresponds roughly to more than $50 \%$ shared variance between correlated variables (Gross et al. 1992).

For statistical analyses IBM SPSS Statistics 19 (IBM Corporation, New York, United States) and EViews6 (IHS EViews, Irvine, United States) were used. In SPSS descriptive statistical analysis was performed, and in EViews all other analyses were carried out.

\section{Results}

\section{Moral Values}

Citizens as one group agreed on the valuation of eight of the twelve factors of the moral values with pig farmers ( $>50 \%$ agreed; Table 4$)$. For the theorems 'function pig is meat for human' and 'meat essential for humans', more than $82 \%$ of the pig 
Table 4 Percentage of respondents per level of agreement (D: disagree (including strongly disagree), N: neutral and A: agree (including strongly agree)) per theorem of the moral values related to pig husbandry of citizens $(n=1607)$ and pig farmers $(n=181)$, and significant differences $(P)$ per theorem between citizens and pig farmers

\begin{tabular}{|c|c|c|c|c|c|c|c|c|}
\hline \multirow[t]{2}{*}{ Element } & \multirow[t]{2}{*}{ Theorem } & \multicolumn{3}{|c|}{ Citizens } & \multicolumn{3}{|c|}{ Pig farmers } & \multirow[t]{2}{*}{$P$} \\
\hline & & $\mathrm{D}$ & $\mathrm{N}$ & A & $\mathrm{D}$ & $\mathrm{N}$ & A & \\
\hline \multirow{3}{*}{$\begin{array}{l}\text { Value } \\
\text { animal }\end{array}$} & Pigs have intrinsic value & 6.3 & 29.6 & 64.1 & 14.4 & 35.4 & 49.6 & 0.06 \\
\hline & Pigs are sentient & 2.7 & 17.3 & 80.0 & 6.1 & 16.0 & 77.3 & 0.07 \\
\hline & Pigs are living beings & 7.2 & 33.6 & 59.2 & 11.7 & 35.9 & 51.8 & 0.59 \\
\hline Hierarchy & Function pig is meat for humans & 22.8 & 37.1 & 40.1 & 1.7 & 15.4 & 82.3 & $<0.01$ \\
\hline \multirow[t]{3}{*}{ Naturalness } & Reproduction should be natural & 4.4 & 30.1 & 65.5 & 22.7 & 35.4 & 42.0 & $<0.01$ \\
\hline & Living conditions should be natural & 3.4 & 23.8 & 72.8 & 38.7 & 39.2 & 21.0 & $<0.01$ \\
\hline & Meat essential for humans & 23.3 & 29.9 & 46.7 & 1.1 & 7.2 & 91.7 & $<0.01$ \\
\hline \multirow[t]{3}{*}{ Justice } & Treat pigs to their own value & 1.6 & 16.8 & 81.6 & 2.2 & 16.6 & 81.2 & 0.61 \\
\hline & $\begin{array}{l}\text { Fair-trade is important in meat } \\
\text { production }\end{array}$ & 2.3 & 16.6 & 81.1 & 4.4 & 14.4 & 80.5 & 0.60 \\
\hline & $\begin{array}{l}\text { Include financial costs in meat } \\
\text { production }\end{array}$ & 3.0 & 19.8 & 77.2 & 0.0 & 1.7 & 97.7 & $<0.01$ \\
\hline \multirow[t]{2}{*}{ Doing good } & Pigs should be individually cared for & 15.4 & 33.6 & 51.0 & 9.9 & 11.6 & 78.5 & $<0.01$ \\
\hline & Pigs should be individually treated & 2.7 & 13.6 & 83.6 & 1.7 & 6.6 & 91.1 & $<0.01$ \\
\hline
\end{tabular}

farmers agreed while $<47 \%$ of citizens agreed. For the theorems 'reproduction should be natural' and 'living conditions should be natural', more than $65 \%$ of citizens agreed while $<43 \%$ of pig farmers agreed. When different clusters of citizens are compared with pig farmers in the valuation of the moral values, differences are shown in seven out of twelve factors of the moral values (Table 5). For the theorems 'pigs are sentient', 'treat pigs to their own value', 'fair trade is important in meat production', 'include financial costs in meat production' and 'pigs should be individually treated' more than $61 \%$ of all groups agreed. For the other theorems pig farmers mostly agreed with citizens in the no-AC cluster $(7.1 \%$ of citizens), followed by citizens in the moderate-AC cluster (38.8\% of citizens). For the theorems 'pigs have intrinsic value', 'pigs are living beings', 'reproduction should be natural' and 'living conditions should be natural', citizens in the high-AC cluster and the max-AC cluster in general agreed more often than pig farmers and citizens in the moderate-AC cluster and the no-AC cluster. This was the other way around for the theorem 'meat is essential for humans', i.e., citizens in the high-AC cluster and the max-AC cluster agreed less often. To the theorem 'function pig is meat for humans' more than $70 \%$ of the no-AC cluster and pig farmers agreed against $<44 \%$ of the other clusters. Citizens in the high-AC cluster and the max-AC cluster mostly agreed with pig farmers $(>62 \%$ agreed) on the theorem 'pigs should be individually cared for'. On this theorem $<36 \%$ of citizens in the moderate-AC cluster and the no-AC cluster agreed.

For the hierarchical position human-pig, more than $79 \%$ of all respondents agreed that pigs are submissive to humans (Table 6). Respondents in the no-AC 
Table 5 Percentage of respondents per level of agreement (D: disagree (including strongly disagree), N: neutral and A: agree (including strongly agree)) per theorem of the moral values related to pig husbandry of clusters $(\mathrm{Cl})$ of citizens and pig farmers $(\mathrm{Pf})$

\begin{tabular}{|c|c|c|c|c|c|c|}
\hline Element & Theorem & Group & $\mathrm{D}$ & $\mathrm{N}$ & A & Not sign. \\
\hline \multirow[t]{15}{*}{ Value animal } & \multirow[t]{5}{*}{ Pigs have intrinsic value } & $\mathrm{Cl1}{ }^{\mathrm{a}}$ & 2.6 & 18.6 & 78.8 & $\mathrm{a}$ \\
\hline & & $\mathrm{Cl} 2$ & 7.9 & 44.3 & 47.8 & \\
\hline & & $\mathrm{Cl} 3$ & 1.8 & 15.6 & 82.7 & \\
\hline & & $\mathrm{Cl} 4$ & 26.3 & 41.2 & 32.5 & \\
\hline & & $\mathrm{Pf}$ & 14.4 & 35.6 & 50.0 & $\mathrm{a}$ \\
\hline & \multirow[t]{5}{*}{ Pigs are sentient } & $\mathrm{Cl1}$ & 1.4 & 10.2 & 88.4 & \\
\hline & & $\mathrm{Cl} 2$ & 3.4 & 26.8 & 69.8 & $\mathrm{a}$ \\
\hline & & $\mathrm{Cl} 3$ & 0.9 & 9.8 & 89.3 & \\
\hline & & $\mathrm{Cl} 4$ & 9.6 & 21.1 & 69.3 & $\mathrm{a}$ \\
\hline & & Pf & 6.1 & 16.1 & 77.8 & $\mathrm{a}$ \\
\hline & \multirow[t]{5}{*}{ Pigs are living beings } & $\mathrm{Cl1}$ & 4.0 & 25.1 & 70.9 & \\
\hline & & $\mathrm{Cl} 2$ & 10.1 & 45.9 & 44.0 & $\mathrm{a}$ \\
\hline & & $\mathrm{Cl} 3$ & 1.3 & 16.9 & 81.8 & \\
\hline & & $\mathrm{Cl} 4$ & 21.1 & 48.2 & 30.7 & \\
\hline & & $\mathrm{Pf}$ & 11.7 & 36.1 & 52.2 & $\mathrm{a}$ \\
\hline \multirow[t]{5}{*}{ Hierarchy } & \multirow[t]{5}{*}{ Function pig is meat for humans } & $\mathrm{Cl1}$ & 31.5 & 36.6 & 31.9 & $\mathrm{a}$ \\
\hline & & $\mathrm{Cl} 2$ & 14.3 & 41.9 & 43.8 & \\
\hline & & $\mathrm{Cl} 3$ & 31.1 & 30.7 & 38.2 & $\mathrm{a}$ \\
\hline & & $\mathrm{Cl} 4$ & 4.4 & 25.4 & 70.2 & $\mathrm{~b}$ \\
\hline & & $\mathrm{Pf}$ & 1.7 & 15.6 & 82.8 & $\mathrm{~b}$ \\
\hline \multirow[t]{15}{*}{ Naturalness } & \multirow[t]{5}{*}{ Reproduction should be natural } & $\mathrm{Cl1}$ & 3.1 & 19.7 & 77.2 & \\
\hline & & $\mathrm{Cl} 2$ & 3.9 & 44.1 & 52.0 & \\
\hline & & $\mathrm{Cl} 3$ & 2.2 & 13.8 & 84.0 & \\
\hline & & $\mathrm{Cl} 4$ & 20.2 & 45.6 & 34.2 & $\mathrm{a}$ \\
\hline & & $\mathrm{Pf}$ & 22.7 & 35.4 & 42.0 & $\mathrm{a}$ \\
\hline & \multirow[t]{5}{*}{ Living conditions should be natural } & $\mathrm{Cl1}$ & 1.1 & 11.0 & 87.9 & \\
\hline & & $\mathrm{Cl} 2$ & 3.9 & 40.8 & 55.4 & \\
\hline & & $\mathrm{Cl} 3$ & 0.0 & 6.2 & 93.8 & \\
\hline & & $\mathrm{Cl} 4$ & 20.2 & 38.6 & 41.2 & \\
\hline & & Pf & 39.1 & 39.7 & 21.2 & \\
\hline & \multirow[t]{5}{*}{ Meat essential for humans } & $\mathrm{Cl1}$ & 32.2 & 29.3 & 38.4 & $\mathrm{a}$ \\
\hline & & $\mathrm{Cl} 2$ & 14.3 & 34.7 & 51.0 & \\
\hline & & $\mathrm{Cl} 3$ & 28.0 & 26.2 & 45.8 & $\mathrm{a}$ \\
\hline & & $\mathrm{Cl} 4$ & 13.2 & 14.9 & 71.9 & \\
\hline & & $\mathrm{Pf}$ & 1.1 & 7.2 & 91.7 & \\
\hline \multirow[t]{5}{*}{ Justice } & \multirow[t]{5}{*}{ Treat pigs to their own value } & $\mathrm{Cl1}$ & 0.5 & 7.4 & 92.1 & \\
\hline & & $\mathrm{Cl} 2$ & 1.9 & 28.7 & 69.3 & \\
\hline & & $\mathrm{Cl} 3$ & 0.0 & 3.1 & 96.9 & \\
\hline & & $\mathrm{Cl} 4$ & 9.6 & 31.6 & 58.8 & \\
\hline & & Pf & 2.2 & 16.6 & 81.2 & \\
\hline
\end{tabular}


Table 5 continued

\begin{tabular}{|c|c|c|c|c|c|c|}
\hline Element & Theorem & Group & $\mathrm{D}$ & $\mathrm{N}$ & A & Not sign. ${ }^{b}$ \\
\hline & Fair-trade is important in meat production & $\mathrm{Cl1}$ & 0.8 & 9.5 & 89.8 & \\
\hline & & $\mathrm{Cl} 2$ & 2.7 & 26.8 & 70.5 & a \\
\hline & & $\mathrm{Cl} 3$ & 0.4 & 4.0 & 95.6 & \\
\hline & & $\mathrm{Cl} 4$ & 12.3 & 26.3 & 61.4 & \\
\hline & & Pf & 4.4 & 14.4 & 81.1 & a \\
\hline & Include financial costs in meat production & $\mathrm{Cl1}$ & 3.3 & 15.5 & 81.2 & a \\
\hline & & $\mathrm{Cl} 2$ & 2.9 & 28.3 & 68.9 & \\
\hline & & $\mathrm{Cl} 3$ & 2.2 & 12.0 & 85.8 & \\
\hline & & $\mathrm{Cl} 4$ & 3.5 & 13.2 & 83.3 & a \\
\hline & & Pf & 0.0 & 1.7 & 98.3 & \\
\hline \multirow[t]{10}{*}{ Doing good } & Pigs should be individually cared for & $\mathrm{Cl1}$ & 10.1 & 27.8 & 62.2 & \\
\hline & & $\mathrm{Cl} 2$ & 21.5 & 46.2 & 32.3 & a \\
\hline & & $\mathrm{Cl} 3$ & 2.7 & 19.6 & 77.8 & $\mathrm{~b}$ \\
\hline & & $\mathrm{Cl} 4$ & 36.8 & 28.1 & 35.1 & a \\
\hline & & Pf & 9.9 & 11.6 & 78.5 & $\mathrm{~b}$ \\
\hline & Pigs should be individually treated & $\mathrm{C} 11$ & 1.2 & 5.9 & 92.9 & a \\
\hline & & $\mathrm{Cl} 2$ & 3.7 & 23.3 & 73.0 & $\mathrm{c}$ \\
\hline & & $\mathrm{Cl} 3$ & 0.9 & 4.4 & 94.7 & $\mathrm{~b}$ \\
\hline & & $\mathrm{Cl} 4$ & 9.6 & 22.8 & 67.5 & $\mathrm{c}$ \\
\hline & & Pf & 1.7 & 6.7 & 91.7 & $\mathrm{a}, \mathrm{b}$ \\
\hline
\end{tabular}

Per theorem, the differences between clusters of citizens and pig farmers were significant unless stated otherwise

a $C l 1$ high-AC cluster $(\mathrm{n}=645), C l 2$ moderate-AC cluster $(\mathrm{n}=623), C l 3$ Max-AC cluster $(\mathrm{n}=225)$, Cl4 no-AC cluster $(\mathrm{n}=114)$, Pf pig farmer $(\mathrm{n}=181)$

b Per theorem, the groups with the same letter (a, b or c) did not differ significantly in percentage of respondents per choice option (strongly disagree, disagree, neutral, agree and strongly agree)

cluster agreed most with pig farmers ( $>97 \%$ agreed on pigs being submissive to humans) and respondents in the high-AC agreed most with respondents in the maxAC cluster (around $80 \%$ agreed on pigs being submissive to humans and around $20 \%$ agreed on pigs being equal to humans).

With regard to naturalness, more than half of all citizens and pig farmers found the freedom of movement and good floor cover important (Table 7). Ad libitum food and water was found important by more than $66 \%$ of citizens in the high-AC cluster and the max-AC cluster against $<50 \%$ of the other clusters and pig farmers finding this important. Less than $45 \%$ of the pig farmers found social contact important, while more than $53 \%$ of all citizens did find this important. For the possibility to go outside and the possibility to grub and mud bathe, only $5 \%$ of the pig farmers indicated to find this important. More than $66 \%$ of citizens in the clusters, except the no-AC cluster, did find this important. Between 43 and $50 \%$ of citizens in the no-AC cluster found this important. 
Table 6 Percentage respondents per hierarchical position with regard to pigs of clusters $(\mathrm{Cl})$ of citizens and pig farmers (Pf)

\begin{tabular}{lllll}
\hline Group & Pig superior to human & Pig equal to human & Pig submissive to human & Not sign. \\
\hline Cl1 & 0.2 & 20 & 79.8 & $\mathrm{a}$ \\
$\mathrm{Cl} 2$ & 0.5 & 9.5 & 90 & \\
$\mathrm{Cl} 3$ & 0 & 20.4 & 79.6 & $\mathrm{a}$ \\
$\mathrm{C} 14$ & 0 & 2.6 & 97.4 & $\mathrm{~b}$ \\
$\mathrm{Pf}$ & 0.5 & 1.7 & 97.8 & $\mathrm{~b}$ \\
\hline
\end{tabular}

The differences between clusters of citizens and pig farmers were significant unless stated otherwise

${ }^{a} C l 1$ high-AC cluster $(\mathrm{n}=645), C l 2$ moderate-AC cluster $(\mathrm{n}=623), C l 3$ Max-AC cluster $(\mathrm{n}=225)$, Cl4 no-AC cluster $(\mathrm{n}=114)$, Pf pig farmer $(\mathrm{n}=181)$

b The groups with the same letter ( $\mathrm{a}, \mathrm{b}$ or $\mathrm{c}$ ) did not differ significantly in percentage of respondents per choice option (superior, equal or submissive)

\section{Relation Moral Values and Attitudes}

Results of the Kendall's Tau rank correlation analysis are shown in Table 8. Even though almost all correlations were significant $(P<0.05)$, correlations had to be 0.6 or higher in order to be meaningful. The only correlations that were found to be useful were those between the valuation of the factor 'living conditions pig must meet natural demands' of the moral values and the levels of importance for the constituents 'possibility to go outside' (correlation of 0.604) and 'possibility to grub and mud bathe' (correlation of 0.603 ) of naturalness.

\section{Discussion}

It was previously shown that attitudes toward sow husbandry differed between pig farmers and citizens (Anonymous 2014). Although moral values are shared by society (Krebs and Denton 2005), we were interested to learn if there was a difference in the weighing of moral values between groups of people with different attitudes toward sow husbandry, viz. pig farmers and four clusters of citizens. Based on literature, we defined thirteen moral values that are commonly shared by society. By means of a questionnaire, citizens and pig farmers could indicate how they would weigh these moral values with regard to sow husbandry. The number of respondents in the group of citizens was higher than the number of respondents in the group of pig farmers. This was the result of using different approaches. Citizens were approached through a research institute with a directory of Dutch citizens representative for the Netherlands who voluntarily participated in surveys, while we approached pig farmers ourselves unannounced. Respondents of pig farmers and citizens differed in socio-demographic features. Pig farmers were assumed to be representative for their group, but citizens were not fully representative of the Dutch population because of relatively older respondents. It is proven that socio-demographic features have an effect on moral values and attitudes toward animal husbandry (Boogaard et al. 2006; Cohen et al. 
Table 7 Percentage of respondents per level of importance (U: unimportant (including highly unimportant), N: neutral, I: important (including highly important)) per constituent of naturalness of clusters (Cl) of citizens and pig farmers (Pf)

\begin{tabular}{|c|c|c|c|c|c|}
\hline Constituents of naturalness & Group & $\mathrm{U}$ & $\mathrm{N}$ & I & Not sign. ${ }^{b}$ \\
\hline \multirow[t]{5}{*}{ Possibility to go outside } & $\mathrm{Cl1}^{\mathrm{a}}$ & 1.6 & 7.3 & 91.2 & \\
\hline & $\mathrm{Cl} 2$ & 2.6 & 29.1 & 68.4 & \\
\hline & $\mathrm{Cl} 3$ & 0.0 & 2.2 & 97.8 & \\
\hline & $\mathrm{Cl} 4$ & 26.3 & 29.8 & 43.9 & \\
\hline & Pf & 74.4 & 20.6 & 5.0 & \\
\hline \multirow[t]{5}{*}{ Social contact } & $\mathrm{Cl1}$ & 1.7 & 11.8 & 86.5 & \\
\hline & $\mathrm{Cl} 2$ & 3.7 & 31.5 & 64.8 & \\
\hline & $\mathrm{Cl} 3$ & 0.0 & 5.3 & 94.7 & \\
\hline & $\mathrm{Cl} 4$ & 20.2 & 26.3 & 53.5 & $\mathrm{a}$ \\
\hline & Pf & 19.3 & 36.5 & 44.2 & $\mathrm{a}$ \\
\hline \multirow[t]{5}{*}{ Freedom of movement } & $\mathrm{Cl1}$ & 0.3 & 2.0 & 97.7 & \\
\hline & $\mathrm{Cl} 2$ & 0.2 & 15.4 & 84.4 & \\
\hline & $\mathrm{Cl} 3$ & 0.0 & 1.3 & 98.7 & \\
\hline & $\mathrm{Cl} 4$ & 5.3 & 21.1 & 73.7 & $\mathrm{a}$ \\
\hline & $\mathrm{Pf}$ & 3.9 & 17.1 & 79.0 & $\mathrm{a}$ \\
\hline \multirow[t]{5}{*}{ Possibility to grub and mud bathe } & $\mathrm{Cl1}$ & 1.6 & 8.2 & 90.2 & \\
\hline & $\mathrm{Cl} 2$ & 2.6 & 30.5 & 66.9 & \\
\hline & $\mathrm{Cl} 3$ & 0.0 & 2.7 & 97.3 & \\
\hline & $\mathrm{Cl} 4$ & 21.9 & 28.9 & 49.1 & \\
\hline & Pf & 76.1 & 18.9 & 5.0 & \\
\hline \multirow[t]{5}{*}{ Good floor cover } & $\mathrm{Cl1}$ & 0.8 & 5.4 & 93.8 & \\
\hline & $\mathrm{Cl} 2$ & 1.4 & 22.6 & 75.9 & $\mathrm{a}$ \\
\hline & $\mathrm{Cl3}$ & 0.0 & 2.7 & 97.3 & \\
\hline & $\mathrm{Cl} 4$ & 3.5 & 21.9 & 74.6 & $\mathrm{a}$ \\
\hline & Pf & 17.2 & 31.1 & 51.7 & \\
\hline \multirow[t]{5}{*}{ Ad lib food and water } & $\mathrm{Cl1}$ & 2.2 & 31.0 & 66.8 & \\
\hline & $\mathrm{Cl} 2$ & 3.4 & 49.3 & 47.4 & $\mathrm{a}$ \\
\hline & $\mathrm{Cl} 3$ & 1.3 & 17.3 & 81.3 & \\
\hline & $\mathrm{Cl} 4$ & 10.5 & 40.4 & 49.1 & $\mathrm{a}$ \\
\hline & $\mathrm{Pf}$ & 32.2 & 35.0 & 32.8 & \\
\hline
\end{tabular}

Per constituent, the differences between clusters of citizens and pig farmers were significant unless stated otherwise

a $C l 1$ high-AC cluster $(\mathrm{n}=645), C l 2$ moderate-AC cluster $(\mathrm{n}=623), C l 3$ Max-AC cluster $(\mathrm{n}=225)$, Cl4 no-AC cluster $(\mathrm{n}=114)$, Pf pig farmer $(\mathrm{n}=181)$

${ }^{\mathrm{b}}$ Per constituent, the groups with the same letter ( $\mathrm{a}, \mathrm{b}$ or $\mathrm{c}$ ) did not differ significantly in percentage of respondents per choice option (highly unimportant, unimportant, neutral, important and highly important)

2012; Frederiksen et al. 2010; Herzog 2007; Knight et al. 2004; María 2006; Prickett et al. 2010; Tuyttens et al. 2010; Kendall et al. 2006). Studies showed that older people have more negative attitude toward animal husbandry with respect to animal welfare than younger people (Bergstra et al. 2013; Frederiksen et al. 2010; Knight et al. 2004). 


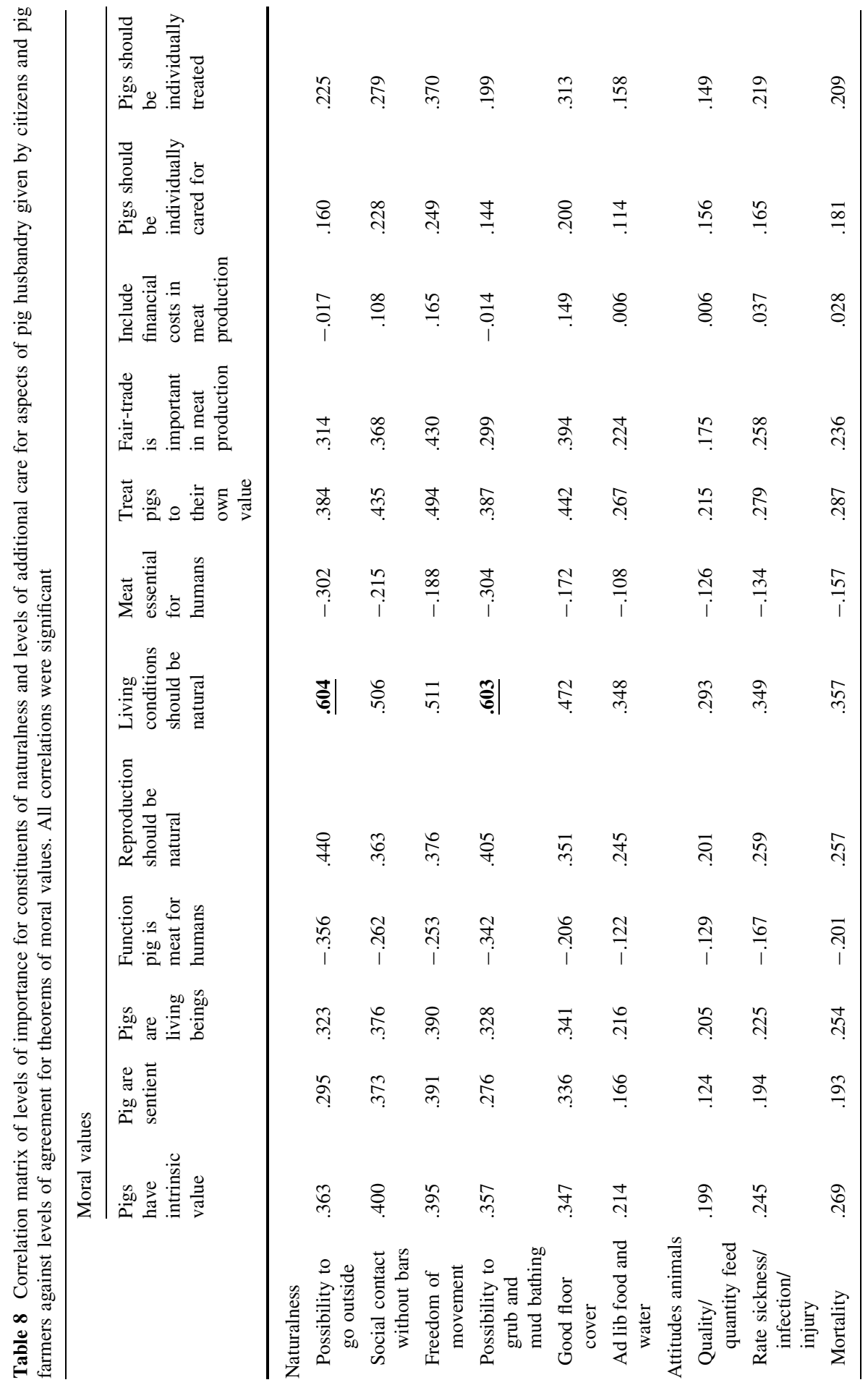




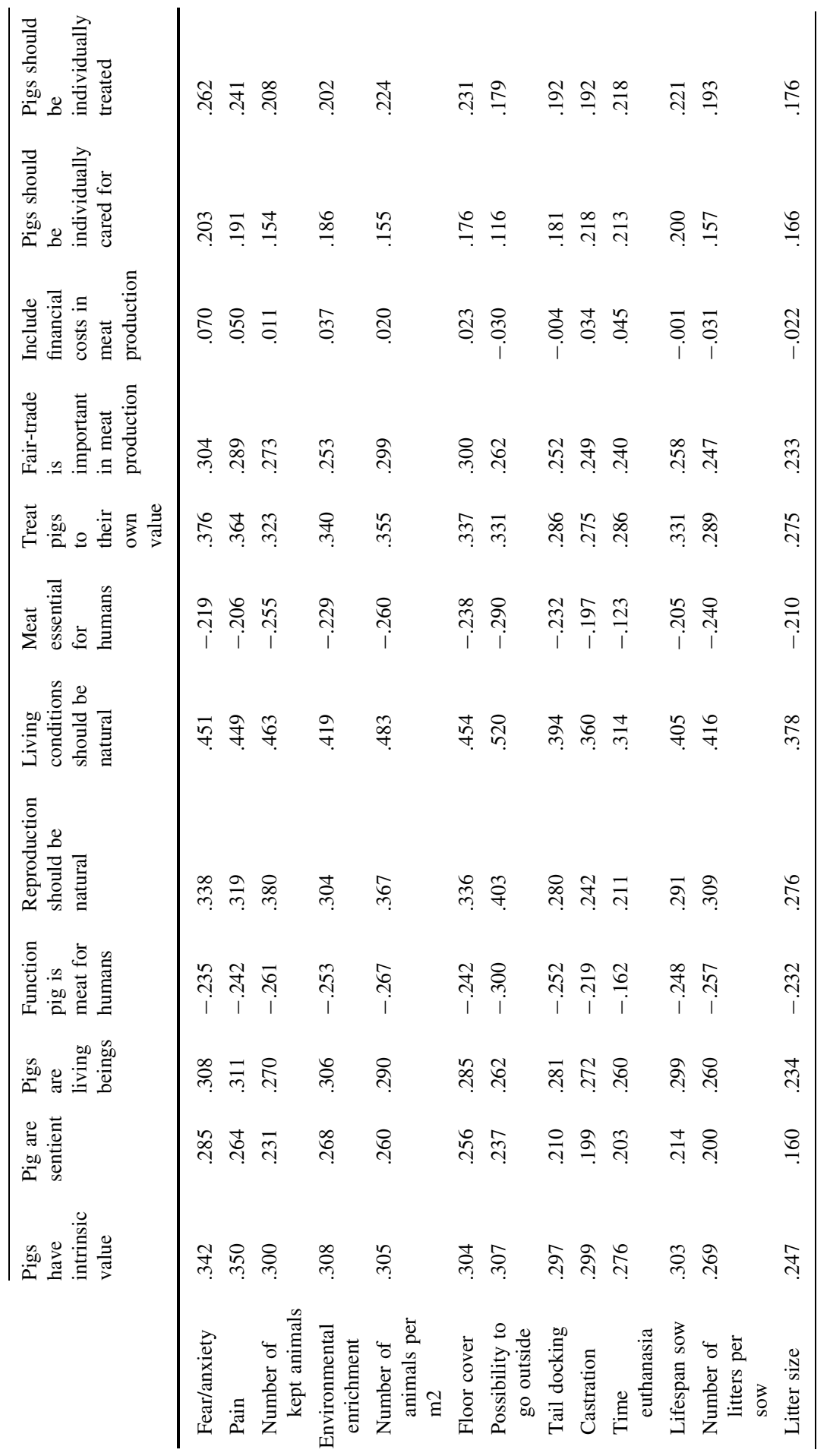




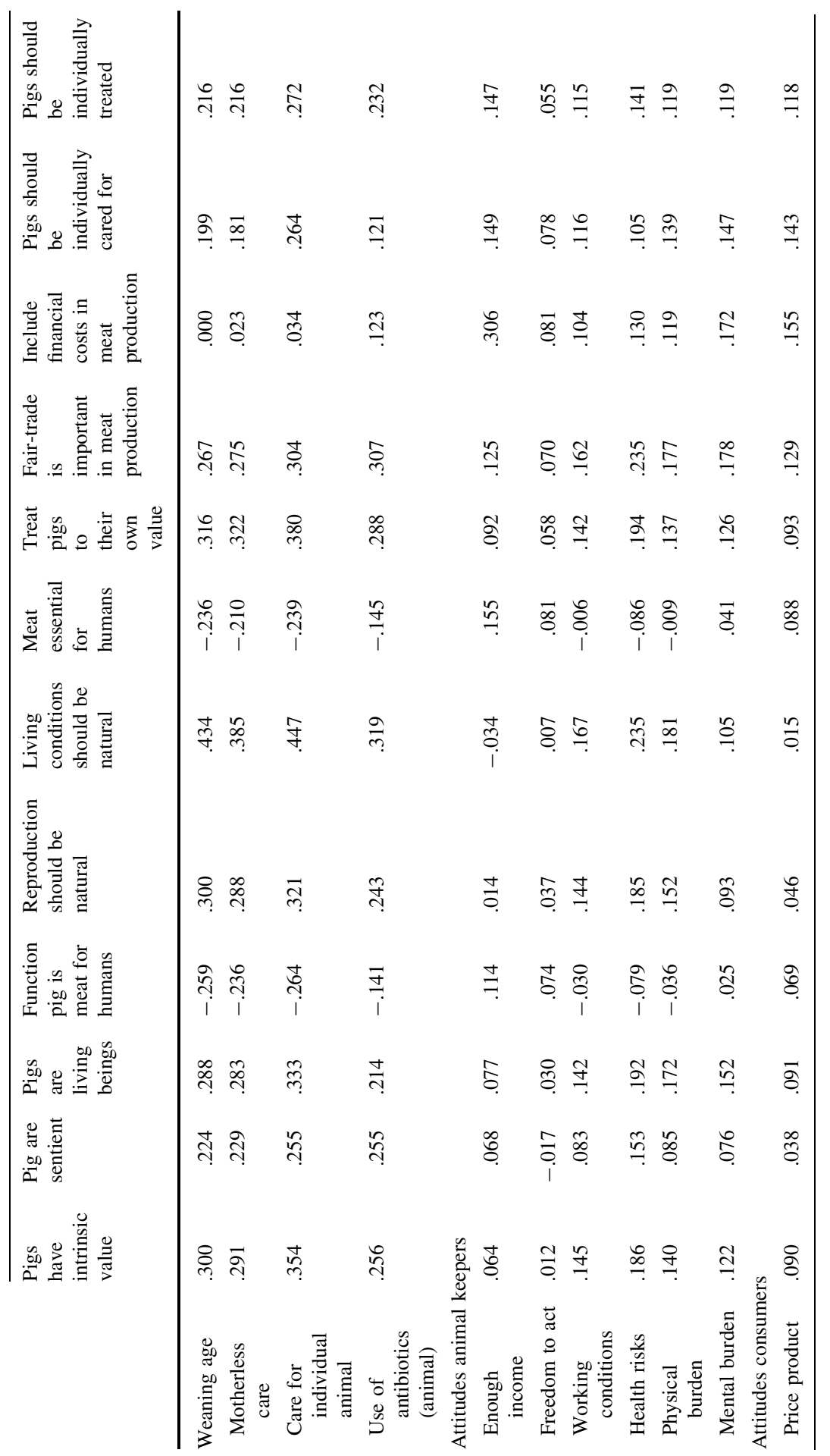




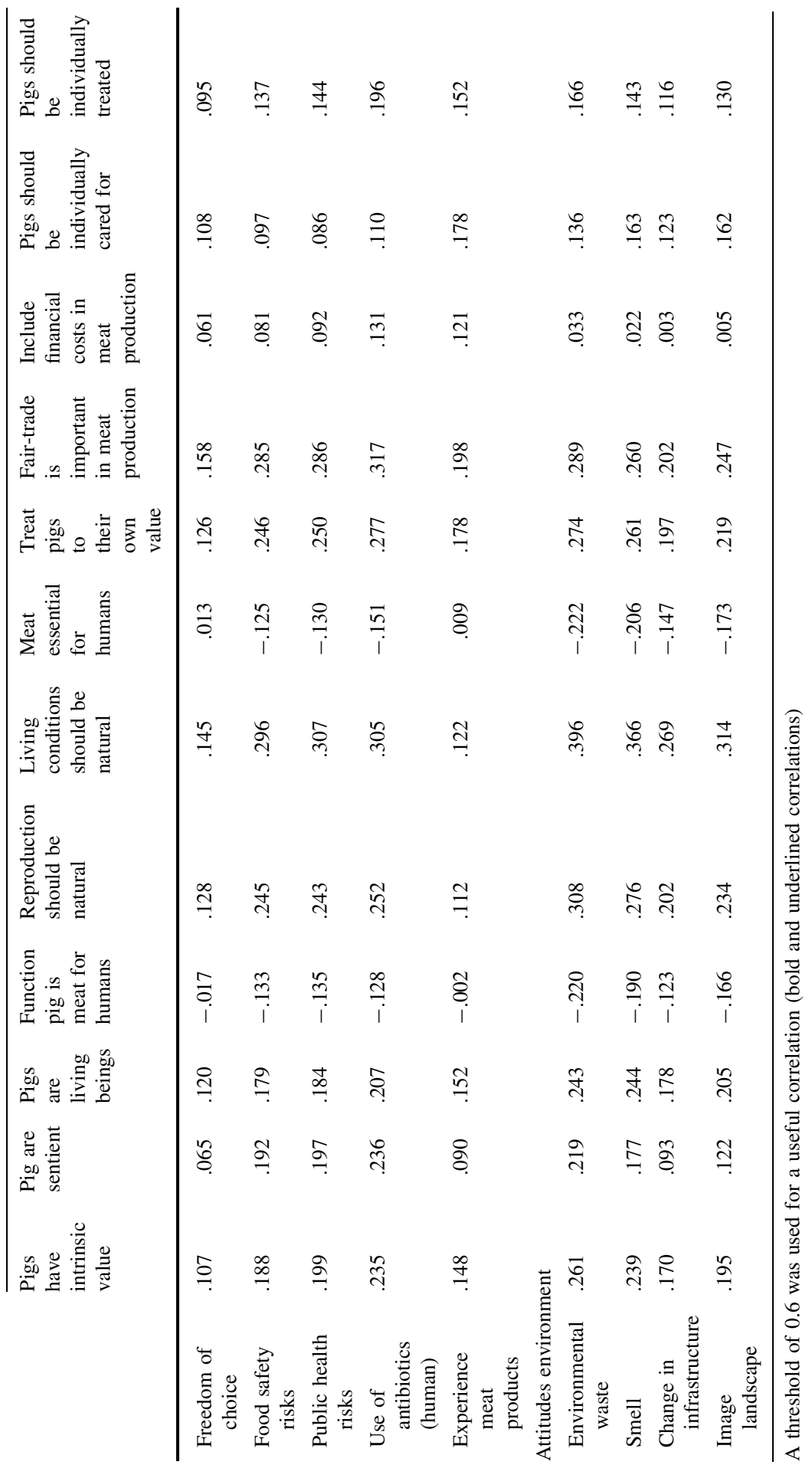


As the group of citizens was not fully representative for the Netherlands, a correction was made for socio-demographic features in the analysis to compare moral values of citizens as a single group and pig farmers. This way it was assured that differences in moral values between these groups were not influenced by socio-demographic features. In the analysis of moral values of different clusters of citizens, based on attitudes toward sow husbandry (Anonymous 2014), and pig farmers this correction was no longer used, because these groups are characterized by their sociodemographic features. This means that respondents in all these clusters were representative for that group.

Based on the results of this study we can confirm the hypothesis that moral values of citizens and pig farmers cannot predict one-on-one the attitudes toward sow husbandry of these groups. Most moral values (nine out of thirteen) were valuated the same by citizens and pig farmers but almost all attitudes toward sow husbandry differed between these groups. This means that, although moral values underlie attitudes (Rokeach 1968), the same set of moral values does not result in the same attitudes toward sow husbandry. Cohen (2010a, b) already stated that a similar valuation of moral values does not result in sharing attitudes toward a specific animal practice. With our result we can support this statement for sow husbandry. However, the valuation of some of the moral values was not shared by citizens and pig farmers. Probably, this different valuation results in different attitudes toward sow husbandry. Moral values are being weighed against other personal values and interest with regard to a context (Cohen et al. 2009), in this case sow husbandry, when forming attitudes. In the context of sow husbandry, pig farmers have different interests than citizens. Pig farmers have an interest in economics (De Greef and Casabianca 2009) and are, therefore, interested in physical animal welfare and production (Bock et al. 2007; Bracke et al. 2005; Van Huik and Bock 2007). Citizens are interested in both physical and mental animal welfare (Te Velde et al. 2002) and find naturalness important (Lassen et al. 2006; Verbeke 2009). That there is a difference in interpretation of naturalness between citizens and pig farmers is shown in this study. Citizens valuated the constituents 'possibility to go outside' and 'possibility to grub and mud bathe' of naturalness much higher than pig farmers. As a consequence, citizens interpret naturalness different than pig farmers. For example, for pigs to have freedom of movement and for the possibility to perform natural behavior, the possibility to go outside and the possibility to grub and mud bathe can be seen as important. The freedom of movement and the possibility to perform natural behavior were, in the present study and in previous studies (Te Velde et al. 2002; Boogaard et al. 2011b), found to be important for both citizens and pig farmers. Citizens interpret the freedom of movement and natural behavior different from pig farmers and give a higher weight to the moral value 'living conditions should be natural'. In interpreting and weighing moral values, for pig farmers the context plays an important role. In the context of sow husbandry, pig farmers consider the possibilities within their farming system with regard to naturalness. For most pig farmers it is difficult to give pigs the possibility to go outside. Therefore, pig farmers search for other solutions for the freedom of movement and the performance of natural behavior of pigs, such as more surface per animal and the possibility to see and hear conspecifics. 
The debate about sow husbandry between citizens and pig farmers is fueled by a difference in attitudes (De Cock Buning 2005). Although attitudes toward sow husbandry cannot be predicted one-on-one by moral values, the valuation of moral values of groups of citizens and pig farmers can be useful in bridging the gap in attitudes toward sow husbandry of these groups. The distance in these attitudes between citizens and pig farmers can be reduced when these groups learn to understand how other groups weigh moral values to form attitudes. The valuation of moral values of pig farmers was the most comparable to citizens in the no-AC cluster. This means that these two groups probably use the same interpretation of moral values when forming attitudes toward sow husbandry. When looking at the attitudes toward sow husbandry (Table 1), pig farmers also seem to share these attitudes most with citizens from the no-AC cluster. Citizens in the max-AC and the high-AC cluster valuated most values differently compared to pig farmers. The difference between these clusters and pig farmers may be explained by the value animals have for humans. Cohen $(2010 \mathrm{a}, \mathrm{b})$ showed that farmers indicated that animals have a functional value, which is mainly a function for humans. In our study this is reflected in the high percentage of farmers $(>82 \%)$ that agreed that the function of pigs is meat for humans and that meat is essential for humans compared to $<45 \%$ of citizens in the high-AC and max-AC cluster. The relationship pig farmers have with animals is that of the 'enlighted ruler'. The 'enlighted ruler' takes the leading role in the relation with animals to improve performance (De Cock Buning 2005). Citizens tend to have more and more a partner relationship with animals (Rollin 2004). The partner looks at the animals as different from humans but not as an unequal party in the relationship (De Cock Buning 2005). Due to this relationship, pigs are seen as different but they should be treated equally to humans and they should not be seen as a commodity for humans.

In our view the valuation of moral values is too distinctive between pig farmers and citizens in the high-AC and max-AC cluster to bridge the gap in their attitudes toward sow husbandry. In order to bridge this gap, the moderate-AC cluster can be helpful. This cluster is a relatively large group of citizens $(39 \%)$ that share the valuation of relatively many moral values, such as pigs have intrinsic value and meat is essential for humans, with pig farmers compared to citizens in the high-AC cluster and the max-AC cluster. Citizens in the moderate-AC cluster do differ from pig farmers in the valuation of some of the moral values, such as 'living conditions should be natural', while they share valuation of these moral values with citizens in the high-AC cluster and the max-AC cluster. This means that citizens in the moderate-AC interpret naturalness in a similar way as citizens in the high-AC cluster and the max-AC cluster. The different valuations of moral values of citizens from the high-AC and the max-AC cluster, citizens from the moderate-AC cluster and farmers can be listed to indicate different levels of valuation of moral values. These different levels can be used in future studies on attitudes toward animal husbandry. In our study we only focused on sow husbandry, but our results can also be interesting for other animal husbandry practices. Also, the framework presented in this paper can be useful in other studies on attitudes and moral values with regard to animal husbandry. When attitudes can be related to levels of valuation of moral values, it is possible to understand where attitudes come from and why certain 
attitudes differ between groups of people. To understand these different attitudes it is useful to focus on the moral values that are valuated differently between groups of people. Even though these groups valuate many moral values similar, those moral values that are valuated differently seem to play an important role in the different attitudes. It is also useful to look at the valuation of moral values that is similar between pig farmers and citizens, because this provides information about the interpretations of moral values that overlap between these groups. Where there is overlap, the different groups interpret moral values similar. This makes it possible for groups to understand each other in the underlying moral values of their attitudes. It is important to look at citizens as different groups as we have shown that clusters of citizens with different attitudes toward sow husbandry, valuate some of the moral values differently. This means that groups of citizens have a different interpretation of sow husbandry. For the pig sector, both pig farmers and policy makers, it is essential to understand the valuation of moral values of the different groups of citizens in order to connect with them when decisions and policies are made and in their communication to the public. Pig farmers can use their understanding of the moral reasoning of citizens in the moderate-AC cluster to learn to understand their interpretation of naturalness. When they understand their interpretation of naturalness they can more easily understand the moral reasoning of citizens in the high-AC cluster and the max-AC cluster. In order to get support from citizens, pig farmers can focus on the moral values that are valuated differently between citizens and pig farmers. For example, citizens value naturalness higher than pig farmers, so pig farmers could focus on naturalness in their housing system. When it is not possible to meet the natural demands of the kept animals, farmers should explain to citizens why this is not possible. On the other hand, citizens could delve into the valuation of moral values of pig farmers in order to understand why certain decisions are made. When citizens and pig farmers understand each other better it is possible to invest in sow husbandry systems that are supported by both pig farmers and citizens.

\section{Conclusions}

To study moral values we developed a theoretical framework of moral values and attitudes related to sow husbandry. Results of a questionnaire, which was based on the framework, show that on average citizens as one group and pig farmers give the same valuation to moral values related to sow husbandry. How these moral values were valuated was not related to attitudes toward sow husbandry, as these were very different between citizens and pig farmers. This means that the hypothesis 'moral values of citizens and pig farmers cannot one-on-one predict the attitudes toward sow husbandry of these groups' is confirmed. A difference in attitudes toward sow husbandry between citizens and pig farmers can be a result of a different weighing and interpretation of moral values. In citizens' interpretation, the constituents 'possibility to go outside' and 'possibility to grub and mud bathe' of naturalness play a role, while these constituents are of no importance for pig farmers. 
The valuation of moral values with regard to sow husbandry differed between clusters of citizens. Citizens in the no-AC cluster had the most similar valuation of moral values as well as the most similar attitudes toward sow husbandry compared to the other clusters. Probably these two groups interpret moral values in the same way when forming attitudes. The valuation of moral values was most different between pig farmers and citizens in the high-AC and max-AC cluster. Moral values of citizens in these groups and pig farmers are too distinctive to bridge the gap in their attitudes toward sow husbandry. As citizens in the moderate-AC cluster share moral values with both pig farmers and citizens in the high-AC and max-AC cluster, this cluster can be useful in bridging the gap in attitudes toward sow husbandry. With knowledge of the different levels of valuation of moral values of the clusters of citizens and pig farmers, it is possible to understand how these different groups interprete moral values when forming attitudes. This understanding can be useful in future research on attitudes toward any type of animal husbandry system, but also for pig farmers and citizens to learn to understand each other's attitudes. With this understanding it is possible to invest in a husbandry system that can build on societal support.

Acknowledgments This article is part of the research project called 'Sow farming in a changing environment' that is funded by the Dutch Ministry of Economic Affairs (EZ) and the Product Board for Livestock, Meat and Eggs (PVE).

Open Access This article is distributed under the terms of the Creative Commons Attribution License which permits any use, distribution, and reproduction in any medium, provided the original author(s) and the source are credited.

\section{References}

Aarts, M. N. C., Te Velde, H. M., \& Van Woerkum, C. M. J. (2001). Hoe oordelen we over de veehouderij? Rathenau Institute. Den Haag, the Netherlands. ISBN 903439282.

Anonymous (2014). Attitudes of Dutch citizens toward animals, humans and the environment with regard to pig husbandry. Submitted.

Anonymous (2015). Attitudes of different stakeholders toward sow husbandry: A study to determine conflicting and matching attitudes toward animals, humans and the environment.

Asseldonk, M. v., Jong, M. d., Vlieger, K. d., \& Huirne, R. (2005). Prevention and control of Foot-andMouth disease, classical swine fever and Avian influenza in the European Union: An integrated analysis of epidemiological, economic, and social-ethical aspects. Wageningen: Wageningen UR.

Barnett, J. L., Hemsworth, P. H., Cronin, G. M., Jongman, E. C., \& Hutson, G. D. (2001). A review of the welfare issues for sows and piglets in relation to housing. Australian Journal of Agricultural Research, 52, 1-28.

Bergstra, T. J., Hogeveen, H., \& Stassen, E. N. (2013). 'Zorgen over zorg' Maatschappelijke zorgen over de varkenshouderij in Nederland. Wageningen, The Netherlands: Wageningen University.

Bock, B. B., \& van Huik, M. M. (2007). Animal Welfare: The attitudes and behaviour of European pig farmers. British Food Journal, 109(11), 931-944.

Bock, B. B., van Huik, M. M., Prutzer, M., Kling Eveillard, F., \& Dockes, A. (2007). Farmers' relationship with different animals: The importance of getting close to the animals. Case studies of French. Swedish and Dutch cattle. pig and poultry farmers. International Journal of Sociology of Food and Agriculture, 15(3), 108-125. 
Boogaard, B. K., Bock, B. B., Oosting, S. J., Wiskerke, J. S. C., \& van de Zijpp, A. J. (2011a). Social acceptance of dairy farming: The ambivalence between the two faces of modernity. Journal of Agricultural and Environmental Ethics, 24, 259-282.

Boogaard, B. K., Boekhorst, L. J. S., Oosting, S. J., \& Sørensen, J. T. (2011b). Socio-cultural sustainability of pig production: Citizen perceptions in the Netherlands and Denmark. Livestock Science, 140, 189-200.

Boogaard, B. K., Oosting, S. J., \& Bock, B. B. (2006). Elements of societal perception of farm animal welfare: A quantitative study in The Netherlands. Livestock Science, 104, 13-22.

Bracke, M. B. M., de Greef, K. H., \& Hopster, H. (2005). Qualitative stakeholder analysis for the development of sustainable monitoring systems for farm animal welfare. Journal of Agricultural and Environmental Ethics, 18, 27-56.

Brom, F. W. A. (2000). Food, consumer concerns and trust: Food ethics for a globalizing market. Journal of Agricultural and Environmental Ethics, 12, 127-139.

Centraal Bureau voor de Statistiek (2011). StatLine. statline.cbs.nl (accessed on December 2011).

Cohen, N. E. (2010a). Considering animals: Moral convictions about animals and judgment on the culling of healthy animals in animal disease epidemics (Vol. Dissertation). Wageningen: Wageningen University.

Cohen, N. E. (2010b). General discussion. In: Thesis: Considering animals. Moral convictions concerning animals and judgement on the culling of healthy animals in animal disease epidemics. Wageningen, The Netherlands: Wageningen University. ISBN 978-90-8585-765-2.

Cohen, N. E., Brom, F. W. A., \& Stassen, E. N. (2009). Fundamental moral attitudes to animals and their role in judgment: An empirical model to describe fundamental moral attitudes to animals and their role in judgment on the culling of healthy animals during an animal disease epidemic. Journal of Agricultural and Environmental Ethics, 22, 341-359.

Cohen, N. E., Brom, F. W. A., \& Stassen, E. N. (2010). Moral convictions about animals and the culling of healthy animals in animal disease epidemics. An emperical survey among farmers and veterinarians. In thesis: Considering animals. Moral convidtions concerning animals and judgement on the culling of healthy animals in animal disease epidemics. Wageningen University. Wageningen, The Netherlands. ISBN 978-90-8585-765-2.

Cohen, N. E., Brom, F. W. A., \& Stassen, E. N. (2012). Moral convictions and culling animals: A survey in the Netherlands. Anthrozoös, 25(3), 353-367.

De Barcellos, M. D., Grunert, Klaus G., Yanfeng Zhou, Y., Verbeke, W., Perez-Cueto, F. J. A., \& Krystallis, A. (2012). Consumer attitudes to different pig production systems: a study from mainland China. Agriculture and Human Values, doi:10.1007/s10460-012-9416-4.

De Cock Buning, T. (2005). The ethics of human-animal relationships. In F. de Jonge \& R. van den Bos (Eds.), The human-animal relationship. Assen. The Nehterlands: Royal Van Gorcum BV.

De Greef, K., \& Casabianca, F. (2009). The Dutch pork chain: A commodity system resisting threats from the market and society. Agriculture, 38(2), 167-174.

Driessen, C. (2012). Farmers engaged in deliberative practices; an ethnographic exploration of the mosaic of concerns in Livestock agriculture. Journal of Agricultural and Environmental Ethics, 25(2), $163-179$.

Duncan, I. J. H. (2006). The changing concept of animal sentience. Applied Animal Behaviour Science, 100, 11-19.

Eagly, A. H., \& Chaiken, S. (1993). The psychology of attitudes. Orlando US: Harcourt Brace Jovanovich College Publishers. ISBN 978-0155000971.

Eagly, A. H., \& Chaiken, S. (1995). Attitude strength, attitude structure, and resistance to change. In J. A. Krosnick \& R. E. Petty (Eds.), Attitude strength antecedents and consequences (4th ed., pp. 413-432). New York: Psychology Press. ISBN 978-0-805-81086-8.

Fraser, D. (1999). Animal ethics and animal welfare science: Bridging the two cultures. Applied Animal Behaviour Science, 65, 171-189.

Fraser, D. (2008). Understanding animal welfare. Acta Veterinarian Scandinavia, 50, S1.

Frederiksen, B., Johnsen, A. M. S., \& Skuterud, E. (2010). Consumer attitudes towards castration of piglets and alternatives to surgical castration. Research in Veterinary Science, 90, 352-357.

Greene, W. H., \& Hensher, D. A. (2010). Modeling ordered choices: A primer. Camebridge, UK: Cambridge University Press. ISBN 978-0-521-19420-4.

Gross, C. R., Lindquist, R. D., Woolley, A. C., Granieri, R., Allard, K., \& Webster, B. (1992). Clinical indicators of dehydration severity in elderly patients. The Journal of Emergency Medicine, 10(3), 267-274. 
Harper, G., \& Henson, S. (2001). Consumer Concerns about Animal Welfare and the Impact on Food Choice. EU FAIR CT98-3678. Centre for Food Economics Research (CeFER). UK.

Harper, G., \& Makatouni, A. (2002). Consumer perception of organic food production and farm animal welfare. British Food Journal, 104(3/4/5), 287-299.

Herzog, H. A. (2007). Gender differences in human-animal interactions: A review. Anthrozoös, $20(1), 14$.

Kendall, H. A., Labao, L. M., \& Sharp, J. S. (2006). Public concern with animal well-being: Place, social structural location, and individual experience. Rural Sociology, 71(3), 399-428.

Knight, S., Vrij, A., Cherryman, J., \& Nunkoosing, K. (2004). Attitudes towards animal use and belief in animal mind. Anthrozoös, 17(1), 43-62.

Krebs, D. L., \& Denton, K. (2005). Toward a more pragmatic approach to morality: A critical evaluation of Kohlberg's model. Psycholological Review, 112(3), 629-649.

Krystallis, A., de Barcellos, M. D., Kügler, J. O., Verbeke, W., \& Grunert, K. G. (2009). Attitudes of European citizens towards pig production systems. Livestock Science, 126, 46-56.

Lassen, J., Sandøe, P., \& Forkman, J. (2006). Happy pigs are dirty!-conflicting perspectives on animal welfare. Livestock Science, 103, 221-230.

Marchant-Forde, J. N. (2009). Introduction to the Welfare of Pigs. In J. N. Marchant-Forde (Ed.), The Welfare of Pigs (Vol. 7, pp. 1-12, Animal Welfare): Netherlands: Springer. ISBN 978-1-40208908-4.

María, G. A. (2006). Public perception of farm animal welfare in Spain. Livestock Science, 103, 250-256.

McGlone, J. J. (2001). Farm animal welfare in the context of other society issues: Towards sustainable systems. Livestock Production Science, 72, 75-81.

Mench, J. A. (2008). Farm animal welfare in the U.S.A.: Farming practices, research, education, regulation, and assurance programs. Applied Animal Behaviour Science, 113, 289-312.

Mepham, B. (2000). A framework for the ethical analysis of novel foods: The ethical matrix. Journal of Agricultural and Environmental Ethics, 12, 165-176.

Meuwissen, M. P. M., \& van der Lans, I. A. (2005). Trade-offs between consumer concerns: An application pork supply chains. Acta Agricultural Scand Section C, 2, 27-34.

Michalopoulos, T., Korthals, M., \& Hogeveen, H. (2008). Trading "ethical preferences" in the market: Outline of a politically liberal framework for the ethical characterization of foods. Journal of Agricultural and Environmental Ethics, 21, 3-27.

Millman, S. T. (2011). Pressure on conventional agriculture (Proceedings of the London swine conference. Exploring the future). London, Ontario.

Ngapo, T. M., Dransfielda, E., Martina, J. F., Magnussonb, M., Bredahlc, L., \& Nuted, G. R. (2003). Consumer perceptions: Pork and pig production. Insights from France, England, Sweden and Denmark. Meat Science, 66, 125-134.

Prickett, R. W., Bailey Norwood, F., \& Lusk, J. L. (2010). Consumer preferences for farm animal welfare: Results from a telephone survey of US households. Animal Welfare, 19, 12.

Rokeach, M. (1968). The role of values in public opinion research. Public Opinion Quarterly, 32(4), $547-559$.

Rollin, B. E. (2004). Annual meeting keynote address: Animal agriculture and emerging social ethics for animals. Journal of Animal Science, 82, 955-964.

Schröder, M. J. A., \& McEachern, M. G. (2004). Consumer value conflicts surrounding ethical food purchase decisions: A focus on animal welfare. International Journal of Consumer Studies, 28(2), 168-177.

Te Velde, H., Aarts, N., \& van Woerkum, C. (2002). dealing with ambivalence: Farmers' and consumers' perceptions of animal welfare in livestock breeding. Journal of Agricultural and Environmental Ethics, 15, 203-219.

Tuyttens, F. A. M., Vanhonacker, F., van Poucke, E., \& Verbeke, W. (2010). Quantitative verification of the correspondence between the welfare quality operational definition of farm animal welfare and the opinion of Flemish farmers, citizens and vegetarians. Livestock Science, 131, 108-114.

Van Huik, M. M., \& Bock, B. B. (2007). Attitudes of Dutch pig farmers towards animal welfare. British Food Journal, 11, 879-890.

Vanhonacker, F., Verbeke, W., van Poucke, E., Pieniak, Z., Nijs, G., \& Tuyttens, F. (2012). The concept of farm animal welfare: Citizen perceptions and stakeholder opinion in Flanders, Belgium. Journal of Agricultural and Environmental Ethics, 25(1), 70-101.

Vanhonacker, F., Verbeke, W., van Poucke, E., \& Tuyttens, F. A. M. (2008). Do citizens and farmers interpret the concept of farm animal welfare differently. Livestock Science, 116, 126-136. 
Verbeke, W. (2009). Stakeholder, citizen and consumer interests in farm animal welfare. Animal Welfare, $18,325-333$.

Verbeke, W. A. J., \& Viaene, J. (2000). Ethical challanges for livestock production: Meeting consumer concerns about meat safety and animal welfare. Journal of Agricultural and Environmental Ethics, $12,141-151$.

Webster, A. J. F. (2001). Farm animal welfare: The five freedoms and the free market. The Veterinary Journal, 161, 229-237. 